\title{
O LUGAR DO TRANSCENDENTAL
}

\author{
The Place of the Transcendental
}

\author{
Alberto Marcos Onate
}

Doutor em Filosofia pela USP. Docente do Curso de Filosofia e do Programa de Mestrado em Filosofia da UNIOESTE-PR. e-mail: am.onate@uol.com.br

\section{Resumo}

Na filosofia contemporânea, um dos temas predominantes é a questão do transcendental. Este artigo pretende tratar da questão a partir do debate entre Husserl e Heidegger. Partindo dos textos pontuais de ambos os pensadores e de um artigo de Jean-François Courtine sobre otema, procura-se mostrarem que medidae segundo quais operadores conceituais as duas abordagens se aproximam e se distanciam.

Palavras-chave: Husserl; Heidegger; Transcendental; Subjetividade.

\begin{abstract}
In the contemporary philosophy, one of the predominant subjects is the question of the transcendental. This article intends to deal with the question from the discussion between Husserl and Heidegger. Based on the specific texts of both the thinkers and in an article of Jean-François Courtine on the subject, it is looked to show in where measured and second which conceptual operators the two approach are close or distant.

Keywords: Husserl; Heidegger; Transcendental; Subjectivity.
\end{abstract}


O diálogo filosófico entre Husserl e Heidegger é pautado por encontros e desencontros, cujo marco decisivo é a publicação de Ser e tempo. Sabe-se, por meio da divulgação dos cursos ministrados pelo segundo, que o afastamento entre ambos os pensadores vinha sendo preparado há anos, mas é a partir da leitura husserliana da obra principal de Heidegger que se consolida a ruptura. Assume-se, no presente artigo, que o núcleo deste debate, entendido enquanto Auseinandersetzung, explicação recíproca, concerne ao estatuto do âmbito transcendental, delineado a partir das noções de eu puro ${ }^{1}$ e de ser-o-aí. ${ }^{2}$ Dum lado, um plano autônomo supérstite ao procedimento de redução fenomenológica do mundo; doutro, um ser-no-mundo que opera transcendentalmente sem recorrer aos parênteses.

\section{I}

Numa importante carta encaminhada a Husserl em 22.10.1927, Heidegger pondera: "Concordamos em que o ente, no sentido do que você nomeia 'mundo', não saberia ser esclarecido em sua constituição transcendental mediante o retorno a um ente do mesmo modo de ser. Mas isto não significa que o que constitui o lugar do transcendental (Ort des Transzendentalen) não seja absolutamente nada de ente; ao contrário, o problema que se coloca imediatamente é de saber qual é o modo de ser do ente no qual o 'mundo' se constitui. Tal é o problema central de Ser e tempo, a saber, uma ontologia fundamental do ser-o-aî". O que está em questão é o estatuto do transcendental, entendido como o âmbito originário a partir do qual mundo pode ser constituído. A concordância assumida por Heidegger diz respeito à insuficiência da abordagem que considera o mundo como fonte de auto-esclarecimento. Mas encerram aí as afinidades, pois a posição heideggeriana é incisiva: a operação transcendental participa de alguma maneira do ôntico, cabendo apenas investigar o modo peculiar em que ela se efetiva. Em Ser e tempo, portanto, como consta na sequiência da carta mencionada acima, "trata-se de mostrar que o modo de ser do ser-o-aí humano é totalmente diferente daquele dos outros

1 Husserl emprega ainda outras designações equivalentes: ego transcendental, ego puro, ego absoluto, eu transcendental, consciência absoluta, consciência pura, consciência transcendental, subjetividade pura, subjetividade transcendental, subjetividade absoluta, etc.

2 Tradução de Dasein proposta por Zeljko Loparic, conforme nota 22 de "Além do inconsciente: sobre a desconstrução heideggeriana da psicanálise". Fenomenologia hoje II: significado e linguagem. 
entes, e que é precisamente em razão deste modo de ser determinado que é o seu, que ele encerra em si a possibilidade da constituição transcendental".

Há algo de maravilhoso (Wundersame) na existência do homem concreto, do si factual, que faz dele muito mais do que um mero fato mundano real: nele ocorre a possibilidade da constituição transcendental. Desde a sua inserção maciça no mundo, enquanto ser-no-mundo, o ser-o-aí envolve uma dimensão instauradora de caráter transcendental, mesmo que ela porventura não seja tratada explicitamente em seus desdobramentos ontológicos. Heidegger prossegue afirmando na mesma carta que "O constituinte não é nada; portanto, algo e ente, embora não num sentido positivo. A questão do modo de ser do próprio constituinte é incontornável". Eis o fio condutor da analítica existencial desenvolvida em Ser e tempo. O constituinte transcendental não precisa ter o conteúdo de suas operações constitutivas colocado entre parênteses para que se vislumbre sua intimidade. Basta efetivar o método apropriado de acesso ao seu modo de ser constituinte, que não exclui, mesmo a título de exercício redutor, a dimensão mundana nele implicada como componente necessário.

Justificam-se assim as indagações heideggerianas no final da carta: "O que se considera o ego absoluto em distinção ao psíquico puro? Qual é o modo de ser deste ego absoluto? Em que sentido ele é idêntico ao eu sempre factual, em que sentido ele não é idêntico? Qual é o caráter da posição mediante a qual o ego absoluto é posto? Em que medida não se trata aqui de nenhuma positividade (ser posto)? A universalidade do problema transcendental". Nestas perguntas, parece anunciar-se o núcleo da dissensão entre os pensadores: o caráter posicional ou não-posicional do lugar do transcendental. Heidegger demanda as credenciais filosóficas do estatuto não-posicional do ego absoluto husserliano, suspeitando detectar nele traços posicionais. O idealismo transcendental, assumido diretamente por Husserl a partir de Idéias I, implica num desposicionamento do campo transcendental, no sentido de que o eu puro torna-se um nada posicional mediante o qual todas as posições mundanas se instauram e se ordenam com sentido. Desde a perspectiva heideggeriana, tal procedimento de redução mostra-se insustentável, pois com ele se perde justamente o que se visa: o mundo.

Para entender as motivações filosóficas da carta enviada por Heidegger a Husserl, deve-se inseri-la em seu contexto: a colaboração dos dois pensadores na redação de um artigo sobre fenomenologia para a Enciclopédia Britânica. A primeira versão foi redigida por Husserl e anotada por Heidegger. A segunda versão foi parcialmente escrita por Heidegger (Introdução e Seção 
I), ficando a seção II a cargo de Husserl, com anotações de Heidegger. ${ }^{3} \mathrm{Na}$ primeira versão, husserliana, voltada a discriminar os domínios das fenomenologias psicológica e transcendental, afirma-se que "Por seu sentido, o problema transcendental implica que sejam questionados o sentido e a validade de toda objetividade conhecida na imanência da subjetividade e identificada no seio de um processo subjetivo de fundação". Considera-se Descartes o formulador inaugural da pura vida subjetiva da consciência como o lugar (Stätte) de toda doação de sentido, de toda posição de ser, de toda verificação de ser. Agregam-se ao marco cartesiano as contribuições de Locke e Brentano, tendose assim o quadro básico inspirador da fenomenologia transcendental. Mas faltou aos predecessores o método de redução transcendental. Por meio dele pode-se acessar a subjetividade absoluta que opera em tudo de maneira subjacente e pode-se abrir à experiência e à vida transcendentais, em cujo âmbito as sínteses intencionais constituem os objetos reais e ideais em suas vigências de ser. Adentrando na experiência transcendental pode-se instaurar uma ontologia a priori com suas estruturas necessárias de um mundo possível, descritas a nível fenomenológico em seus modos de doação de sentido e de fundação de ser. Assim, "o subjetivismo só pode ser superado pelo mais universal e conseqüente subjetivismo (o transcendental). Dessa forma, ele é simultaneamente objetivismo". A polaridade sujeito-objeto, junto com o mundo por ela estruturado, só pode ser esclarecida em sua origem mediante o abandono radical daquilo que os pólos, naturalmente considerados, implicam, subsumindoos em todos os aspectos na dimensão operatória transcendental.

Os trechos da segunda versão atribuídos a Heidegger denotam um típico deslocamento conceitual em relação à primeira versão. A história da filosofia é considerada enquanto pergunta pelo ser do ente, numa conversão gradativa, mas sistemática, da visada dirigida ao ente para aquela dirigida à consciência. O papel da fenomenologia é justamente esclarecer a necessidade do retorno à consciência, explicitar como se dá tal retorno e descrever o campo da subjetividade pura. Tarefa que demanda uma separação entre os planos da psicologia pura e da ciência transcendental da subjetividade pura. A psicologia pura implica uma conversão dos vividos orientados a objetos, tornando os próprios vividos em objetos investigados, ou seja, em fenômenos a serem elucidados em suas estruturas, graus e conexões. A característica essencial desses vividos é que eles são intencionais, sempre orientados a algo, e cujas formas essenciais remontam a uma típica determinada pelas sínteses e pelos processos

3 HUSSERL Edmund. Husserliana - Band IX. Phänomenologische Psychologie. Den Haa: Martinus Nijhoff, 1962. p. 237-277.

Rev. Filos., v. 19, n. 24, p. 131-145, jan./jun. 2007 
possíveis no âmbito de um encadeamento psíquico fechado, de um si singular em geral. A análise eidética desse psíquico puro depende de uma redução psicofenomenológica capaz de elucidar as conexões puras entre a intenção e o intencionado, mediante a descrição dos invariantes inerentes à livre variação das possibilidades, do necessário estilo formal dos vividos. Procedimento redutor que deve ser ampliado para incluir os outros eu mediante a descrição das relações empáticas, transformando-o assim em redução intersubjetiva.

A parte final da segunda versão cabe a Husserl, com anotações importantes de Heidegger. Retoma-se a distinção entre psicologia fenomenológica e fenomenologia transcendental. De Descartes a Brentano, passando por Locke e Hume, tal distinção não foi consumada, por confundirse positividade e transcendentalidade. Faltava assumir radicalmente a atitude transcendental e, assim, abandonar a atitude natural, mediante o método de redução fenomenológica. A redução psico-fenomenológica é considerada circunscrita, pois a questão do transcendental concerne ao sentido de um mundo em geral cujo sentido e validade decorrem das produções (Leistungen) da consciência. Compete à filosofia transcendental consumar uma epoché irrestrita em relação ao mundo, validando apenas a subjetividade pura em sua autoexperiência absoluta.

Contexto da exposição husserliana no qual Heidegger anota: "Não pertence à essência do ego puro um mundo em geral? Conforme nosso diálogo em Todtnauberg (1926) sobre o 'ser-no-mundo' (Ser e tempo I, §§ 12 e 69) e a diferença essencial com o ser-subsistente 'no interior' de tal mundo". Quando, na sequiência do texto, Husserl assevera que, mediante a redução transcendental, não pode mais se considerar um eu humano (menschliches Ich), Heidegger pondera: "Ou talvez precisamente tal, em sua mais própria, 'maravilhosa' possibilidade de existência. Conforme p. 17, em que você fala de um 'modo de modificação da forma de vida'. Por que não? Esta ação não é uma possibilidade do humano, mas justo por que este nunca é subsistente, um comportamento (Verhalten), isto é, um modo de ser que por sua constituição própria cria a si e, portanto, não pertence à positividade do subsistente". Para Heidegger, na redução transcendental ocorre uma "ascendência (subida) que permanece 'imanente', uma possibilidade humana, na qual o homem justamente chega a si próprio". Ou, expressando melhor, deve-se considerar que o próprio processo redutivo não desconecta nada, não coloca nada entre parênteses, como formulava Husserl, dando lugar apenas a uma conversão imanente, a uma modificação intrínseca da vida humana em que o mundo é reconhecido em sua mundanidade desde o interior de um esclarecimento do caráter ontológico desta vida. 
Diferenças de concepção que se tornam mais tangíveis quando se consideram alguns textos individuais dos pensadores nesse período. No curso ministrado em Marburg no verão de 1927, publicado no volume 24 da Gesamtausgabe sob o título "Os problemas fundamentais da fenomenologia", Heidegger explicita sua acepção peculiar do método fenomenológico. Importa, sobretudo, caracterizar as estruturas metódicas da diferenciação transcendentalontológica. O caráter a priori do ser e de todas as estruturas ontológicas exige um tipo de acesso específico e um modo determinado de apreensão do ser, pertencente ao vasto campo de conhecimento apriorístico chamado de fenomenologia. Enquanto método, a fenomenologia remonta ao começo da própria filosofia, não podendo circunscrever-se ao movimento filosófico que no século XX recebeu tal denominação. Trata-se, desde os primórdios, de apreender o ser a partir da vigência dos entes.

Um dos componentes do método fenomenológico heideggeriano diz respeito, numa concessão meramente terminológica a Husserl, à redução fenomenológica. Em vez da passagem metódica husserliana da atitude natural à atitude transcendental da consciência com seus vividos noético-noemáticos constitutivos de qualquer objetividade, para Heidegger, a redução fenomenológica designa "a recondução da visada fenomenológica da apreensão do ente, qualquer que seja sua determinação, à compreensão do ser deste ente". Tal redução, cuja diretriz metódica é de cunho negativo, deve ser complementada por uma atitude construtiva em relação ao próprio ser, na qual este seja abordado desde si em consonância a um projeto livre de compreensão. Para completar o método fenomenológico, falta o componente de desconstrução (Abbau) dos conceitos ontológicos herdados da tradição, não para abandoná-los, mas para apropriá-los criativamente.

Os três componentes do método fenomenológico são articulados pela estrutura dos comportamentos do ser-o-aí, ou seja, pela intencionalidade em sua versão heideggeriana. Nela engloba-se tanto a intenção quanto o intencionado de todo comportamento, sem considerá-la uma relação objetiva entre entes subsistentes. É a intencionalidade que põe toda objetividade e subjetividade, e não o contrário. Os comportamentos intencionais do ser-o-aí, entendidos em si próprios, não provêm de nenhuma interioridade ou exterioridade, sendo estas meros produtos derivados daqueles. Cabe aqui uma pergunta decisiva: como determinar o modo-de-ser do ser-o-aí a partir dos comportamentos intencionais, como ele se revela a si em sua existência? O dirigir-se a intencional não provém da atividade de um centro egóico, mas se instaura desde este próprio visar. O si é presente ao ser-o-aí mesmo sem reflexão ou autopercepção, sendo esta apenas um dos modos de auto-revelação. A relação 
a si do ser-o-aí opera conforme um sentido ampliado do termo reflexão, em cuja vigência sua ipseidade se mostra refratando-se nos entes com que se ocupa e se preocupa. O ser-o-aí é determinado existencialmente por uma transposição prévia, por uma transcendência constitutiva que o põe sempre com aquilo que é posto. O ser-o-aí, enquanto ser-no-mundo, existe sempre num mundo ambiente (Umwelt). Mundo é entendido na fenomenologia heideggeriana não como sinônimo de natureza, de conjunto dos entes que integram o universo, mas como o a priori que é previamente compreendido na existência do ser-o-aí, antes da apreensão de qualquer ente particular. Existir significa projetar um mundo, de tal maneira que com o ser-lançado deste projeto o ente subsistente já é descoberto em seu caráter ontológico. Por outro lado, constituído estruturalmente por tal projeto, o ser-o-aí sai de si, ex-sistere, é no mundo.

Qual a resposta de Husserl à concepção heideggeriana do ser-oaí? Um dos textos mais significativos concernentes à polêmica é a conferência Fenomenologia e antropologia. ${ }^{4}$ Embora Heidegger não seja mencionado, monta-se o cenário teórico para acusar sua filosofia de antropológica, limitada em seu estatuto fundante e ontologicamente ingênua. Inspirando-se nas Meditações de Descartes enquanto modelo formal de investigação e descartando vários de seus conteúdos peculiares, detecta-se a fragilidade da certeza ontológica na experiência do mundo e consuma-se a epoché universal, cujo resíduo semântico é o eu puro: "Enquanto este ego apodítico, eu sou, em relação ao ser do mundo, o anterior em si, e isto na medida em que meu ser, enquanto este ego, permanece intacto qualquer que seja a validade ontológica do mundo e de sua justificação". O mundo continua a aparecer, mas colocado entre parênteses, puro e simples fenômeno. Instaura-se o campo transcendental de experiência e conhecimento, abordando o eu transcendental e suas cogitationes, para descrever como ele confere sentido e validade ao mundo em sua relatividade transcendental. Começa-se apreendendo a típica essencial dos vividos de consciência em sua temporalidade imanente. Abordam-se as cogitationes puras em suas particularidades, bem como suas interconexões, para depois vinculálas às faculdades puras correspondentes. O que é dado ingenuamente como objeto uno torna-se o fio condutor transcendental para a descrição sistemática das multiplicidades de visadas puras que lhe pertencem essencialmente. Horizonte de tarefas fenomenológicas indutoras do diagnóstico husserliano, cujo alvo implícito é a posição heideggeriana:

\footnotetext{
4 Pronunciada em 01, 10 e 16/06/1931 em Frankfurt, Berlim e Halle. Publicada HUSSERL, Edmund. Husserliana-Band XXVII: Aufsätze und Vorträge (1922-1937). The Hague: Kluwer Academic Publisher, 1988.
} 
É logo claro que toda doutrina do homem, empírica ou apriorística, pressupõe um mundo existente ou suscetível de existir. A filosofia do sero-aí humano cai, pois, nesta ingenuidade que é preciso superar, o que é, a nosso ver, todo o sentido dos tempos modernos. Uma vez tal ingenuidade desvelada, uma vez atingido o autêntico problema transcendental em sua necessidade apodítica, não se saberia mais ali retornar. (HUSSERL, 1988).

\section{II}

No artigo L'idée de la phénoménologie et la problématique de la réduction, Jean-François Courtine ${ }^{5}$ discute a relação Husserl-Heidegger em consonância à questão do transcendental, acrescentando-lhe alguns aspectos relevantes. Courtine assume que Heidegger retoma a redução husserliana e se pergunta: "qual é o destino da redução na obra de Heidegger e em particular em Sein und Zeit, que forma ela toma, a que inversão ela se submete?" O intérprete francês considera que a analítica do ser-o-aí desenvolvida em Ser e tempo constitui uma radicalização da epoché husserliana, sobretudo mediante a análise da disposição fundamental da angústia (Grundbefindlichkeit der Angst).

Courtine realça que a questão condutora na qual se insere a abordagem heideggeriana da angústia concerne à totalidade originária da estrutura total do ser-o-aí. ${ }^{6} \mathrm{O}$ fenômeno da angústia (Phänomen der Angst) revela ao ser-o-aí a totalidade de suas determinações estruturais. Além disso, a angústia revela ainda o mundo enquanto tal. Para cumprir ambas as funções, a angústia coloca todo ente intramundano sob o regime da insignificância, da indiferença. Eis o paralelismo com o procedimento redutor husserliano, pois na angústia ocorre de certo modo uma colocação do mundo entre parênteses, revelando o nada de mundo. Como em Husserl, tal redução não é meramente negativa, pois só mediante ela manifesta-se a possibilidade do mundo enquanto tal e o ser-o-aí torna-se acessível a si em suas estruturas determinantes.

5 Incluído no livro Phénoménologie et métaphysique. Entre outros textos que também abordam esta relação, podem-se citar como relevantes os artigos La fenomenologia fra soggettività e mondo, de Vincenzo Costa e La naissance de l'ego husserlien et la révélation du DaseinEtude de la phénoménalisation de l'ipséité chez Husserl et Heidegger, de Paul Duquaire.

6 Conforme o título do parágrafo 39 de Ser e tempo. 
Entretanto, a angústia heideggeriana não remete a nenhuma apreensão retrospectiva decorrente de uma reflexão imanente. Ela não é produto de uma análise das vivências puras ou de um exercício da intuição pura. A angústia irrompe em consonância à sua dinâmica própria e torna o ser-o-aí estranho (unheimlich), desprovido da familiaridade com o mundo. Assim, ela libera o ser-o-aí não da tese da atitude natural, como no caso da redução husserliana, mas sim da decadência (Verfallen), colocando-o diante de seu poderser mais próprio, no qual o mundo acede à compreensão.

A partir deste cenário teórico de proximidades e distanciamentos, Courtine conclui: "A angústia redutora não marca 'o verdadeiro abismo de sentido' que separa a 'consciência' e a 'realidade', mas ela revela mais originariamente o Dasein ele próprio como Da-sein, como o lugar ${ }^{7}$ mesmo da Diferença. A recondução operada pela angústia desvela 'o evento fundamental de nosso ser-o-aí."

Abdicando a aquilatar, neste artigo, a pertinência e o alcance da interpretação de Courtine, realço a precisão das determinações nela associadas ao eu puro e ao ser-o-aí: o caráter não-posicional, de decisão e de reflexão do primeiro e o caráter posicional, de irrupção e de disposição do segundo. É, sobretudo, a partir deles que Husserl e Heidegger se propõem a pensar o lugar do transcendental. Não se trata, porém, de propriedades naturais, em consonância ao vocabulário husserliano, nem de propriedades ônticas, conforme o vocabulário heideggeriano. Tais caracterizações devem ser compreendidas num âmbito estritamente fenomenológico. ${ }^{8}$ Concentro-me, na sequiência do texto, embora de modo sucinto, nos componentes mais relevantes do terceiro binômio (reflexão/disposição), entendidos como vias privilegiadas, embora divergentes, de compreensão do âmbito transcendental.

7 Grifo meu.

8 No final do texto Meu caminho para a fenomenologia, Heidegger afirma: "Parece que o tempo da filosofia fenomenológica passou. Já é julgada como algo passado, que é apenas consignado ainda historiograficamente ao lado de outros movimentos filosóficos. Entretanto, a fenomenologia não é nenhum movimento, naquilo que lhe é mais próprio. Ela é a possibilidade do pensamento - que periodicamente se transforma e somente assim permanece - de corresponder ao apelo do que deve ser pensado. Se a fenomenologia for assim compreendida e guardada, então pode desaparecer como expressão, para dar lugar à questão do pensamento, cuja manifestação permanece um mistério. Post Scriptum de 1969 - O sentido da última frase já vem expresso em HEIDEGER, Martin. Sein und Zeit. Tübinger: Niemeyer, 1922. Tradução brasileira: Ser e tempo. Márcia Schuback. 2v. Petrópolis: Vozes, 1989. p. 38. 'O essencial para ela (a fenomenologia) não consiste em realizar-se como 'movimento' filosófico. Acima da atualidade está a possibilidade. Compreender a fenomenologia quer unicamente dizer: captála como possibilidade". 
Na lição 40 e seguintes do segundo volume da Filosofia primeira, Husserl trata de maneira pontual da noção de reflexão. Serve-lhe de exemplo condutor a percepção de uma casa. No ato perceptivo, o eu que percebe abandona-se ao percebido e esquece-se, de certo modo, de si e, sobretudo, do ato de perceber. Na reflexão, a atitude de abandono ingênuo ao objeto é transformada em tema e apreendida enquanto tal. Nesta apreensão reflexiva, o perceber ingênuo e o eu que o percebe pertencem ao passado: ambos são apreendidos mediante uma retrocepção (Zurückgreifen), denominada por Husserl de retenção (Retention). Caso o ato perceptivo prossiga enquanto opera o eu reflexivo, não ocorre mais separação entre ambos, pois no presente vivo (lebendige Gegenwart) coexistem o eu desdobrado e o ato desdobrado do eu. Por sua vez, o eu reflexivo e seu ato de apercepção também operam sob a dinâmica do esquecimento e, para que haja uma apreensão deste esquecimento em segundo grau, faz-se necessário um ato reflexivo de segundo grau com um eu correspondente, ambos novamente esquecidos de si. Reiterando-se tais desdobramentos, tem-se a passagem contínua de eus latentes a eus patentes. Todo eu reflexivo atual toma por objeto o eu antes latente para transformá-lo em objeto intencional.

A vida egológica é um processo contínuo de desdobramentos, sem que isto signifique uma multiplicação indevida de eus. É o mesmo eu que atua em todos os seus atos reflexivos, cada vez de modo diferente: desdobrando-se numa multiplicidade de atos e de sujeitos de atos, é sempre o mesmo eu que se desdobra, auto-apreendido mediante uma identificação sintética evidente. O que permanece constante na série de desdobramentos é, no exemplo adotado, a crença perceptiva: seja no modo perceptivo imediato ou nos diferentes modos reflexivos nele baseados, o objeto percebido tem uma validade inconteste de existência. Tal constatação concernente aos atos perceptivos aplica-se também aos outros atos: imaginativos, mnemônicos, volitivos, sentimentais, etc. Em todos eles o eu, no modo natural ou reflexivo, é interessado no ser de seus objetos intencionais. Mesmo na negação de parte ou do todo do evento experimentado, imaginado, lembrado, etc., o interesse a ele dirigido não é desconectado. Pode ocorrer, inclusive, divergência de interesses entre o eu em seu modo natural e o eu em seu modo reflexivo, ou entre os diferentes tipos de atos vigentes a cada vivência do eu, sem que a atitude interessada seja abandonada.

Só um exercício extremo de liberdade pode desvencilhar o eu de suas crenças naturais ou reflexivas no ser de seus objetos intencionais, 
convertendo-o assim num contemplador absolutamente desinteressado. ${ }^{9}$ Para atingir enfim um grau absoluto de imparcialidade, o eu precisa radicalizar sua atividade reflexiva, orientando-a a uma reflexão fenomenológica. Nela, o mundo natural, a atitude natural e a própria reflexão natural interessada são convertidos transcendentalmente. $\mathrm{O}$ novo passo redutor consiste, num primeiro momento, em refletir sobre os próprios atos reflexivos. Embora de modo mais recuado, eles mantêm certo grau de interesse pelos componentes de crença inerentes aos atos sobre os quais operam. Faz-se necessário, portanto, avançar no procedimento redutor, universalizá-lo. $\mathrm{O}$ conceito-chave diz respeito à consciência-de-horizonte. ${ }^{10}$ Retomando o exemplo da percepção de um objeto qualquer, nota-se que ela implica num horizonte interno e noutro externo de consciência, ambos indeterminados e vazios de intuição, embora não vazios de sentido, desprovidos de validade. Horizontes cujas implicações intencionais formam, em última instância, as diferentes modulações temporais, espaciais e egológicas. São eles que possibilitam a universalização da epoché mediante a totalização dos correlatos intencionais do eu que opera em sua pureza, transformando o universo mundano em objetividade intencional universal. A operação com estes horizontes intencionais abre ao eu puro um novo campo de experiência: a experiência transcendental, âmbito em que toda verdade e toda ciência possíveis fundam-se sobre uma justificação absoluta.

De sua parte, Heidegger, no parágrafo 29 de Ser e tempo, caracteriza o ser-o-aí como disposição. Determinação ontológica que tem seu equivalente ôntico no humor (Stimmung). Disposição diz muito mais do que estado anímico de qualquer ente humano e não pode ser apreendida de maneira reflexiva como se fosse uma vivência dele. ${ }^{11}$ A disposição não provém nem de dentro nem de fora deste ente, ela é antes o modo existencial básico da abertura originária de mundo. $\mathrm{O}$ ente humano, enquanto ser-o-aí, encontra-se constitutivamente determinado por disposições. Dominá-las, no sentido de atuar acima delas, sem elas, significa, no fundo, escamotear em diversos níveis as dinâmicas de suas instaurações sob o comando sub-reptício de outras disposições. Todos os sentidos, onticamente considerados, só podem operar porque pertencem a um ente cujo modo de ser é disposto no mundo. Todo ente intramundano só afeta os sentidos, vem ao encontro deles, mediante as disposições constitutivas do ser-o-aí.

9 Designação grifada pelo próprio Husserl no final da lição 40 de Filosofia Primeira.

${ }_{10}$ Hintergrundbewusstsein. Uma alternativa legítima de tradução é consciência-de-fundo. A escolha feita deve-se à interpretação filosófica do conceito husserliano.

11 Visando Husserl sem nomeá-lo, Heidegger diz que "mesmo a mais pura teoria não conseguiu ultrapassar todos os humores". 
Investigar as disposições implica em deixá-las ser, e não em alcançálas mediante artifícios teóricos. Elas se encontram enraizadas no aí do ser-o-aí, cabendo ao investigador deixá-las despertar existencialmente e expor suas estruturas básicas de manifestação. Assim encaradas, elas são o princípio de consistência e de possibilidade do ser-o-aí, são o âmbito a partir do qual ocorrem tanto seu pensamento quanto sua ação. No léxico heideggeriano, elas são a essência do ser-o-aí.

Entre as disposições fundamentais, Heidegger privilegia duas: a angústia e o tédio (Langeweile). ${ }^{12}$ Elas são consideradas fundamentais porque mobilizam integralmente o ser-o-aí, transpassando-o, colocando-o numa situação privilegiada de questionamento em relação ao estatuto de si e do mundo. Na primeira, "o angustiar-se abre, de maneira originária e direta, o mundo enquanto mundo. Não é antes a reflexão que abstrai do ente intramundano para só então pensar o mundo e, em consequiência, surgir a angústia nesse confronto. Ao contrário, enquanto modo da disposição, é a angústia que pela primeira vez abre o mundo enquanto mundo" (Ser e tempo, § 40). Na segunda, ocorre "o banimento do horizonte temporal; este banimento faz com que seja eclipsado o instante pertinente à temporalidade, para impelir, em tal eclipse, o ser-o-aí banido para o interior do instante como o elemento propriamente possibilitador de sua existência; e esta existência só é possível em meio ao ente na totalidade, que se recusa no horizonte do banimento justamente na totalidade" (Conceitos fundamentais da metafísica, § 34). A explicação heideggeriana de ambas as disposições fundamentais indica que elas se efetivam desde uma dimensão transcendental, ou seja, viabilizam o acesso às estruturas de abertura do mundo enquanto totalidade. O ser-angustiado associa-se à questão do nada, ao passo que o ser-entediado liga-se mais diretamente à questão do tempo, ambos remetendo, no limite, à questão do ser.

No cerne da bifurcação das duas tendências compreensivas do modo de acesso ao transcendental, o que se encontra em discussão é aquilo que Heidegger denomina de campo fundamental da investigação fenomenológica. ${ }^{13}$ As implicações filosóficas da descrição da consciência pura entrelaçam-se àquelas da analítica do ser-o-aí. Desde a perspectiva heideggeriana, isto significa que, embora a fenomenologia husserliana traga

12 A primeira é abordada, entre outros textos, em Ser e tempo e em Que é metafísica?. O tédio recebe um tratamento detalhado em Os conceitos fundamentais da metafísica: mundo, finitude, solidão. Atenho-me aos componentes conceituais relevantes para o tema condutor deste artigo.

13 Conforme o título do parágrafo 12 de Prolegômenos para uma história do conceito de tempo. Curso ministrado em Marburgo no semestre de verão de 1925. 
descobertas importantes, a elaboração de seu campo temático exclui justamente o decisivo: abordar radicalmente o ser da consciência pura. As caracterizações desta como ser imanente, dado absoluto, região independente do que a transcende e estrutura essencial de puras vivências não atendem ao lema original de volta às coisas mesmas, revelando antes uma subordinação insuspeitada à tradição filosófica, sobretudo aquela de matriz cartesiana, em que o resultado é sempre algo de objetivo dado previamente.

Reduzir fenomenologicamente toda posição mundana e operar a partir do resíduo de consciência pura não equivale, para Heidegger, a radicalizar a démarche cartesiana. Além de prescindir da realidade dada, a redução husserliana abdica ainda à individuação correspondente dos atos em que aquela se dá. Os atos são considerados estritamente em suas estruturas e em suas relações estruturais, desconsiderando-se a investigação sobre o ser dos atos, sobre sua existência. Lacuna decorrente do interesse primeiro de Husserl na elaboração de uma teoria da razão, na qual se privilegiam os modos de constituição na consciência pura das diferentes regiões de ser, determinandose suas respectivas realidades de acordo as visadas desta consciência. Circunscrição do horizonte temático que mune o severo diagnóstico heideggeriano:

\begin{abstract}
A fenomenologia, na tarefa fundamental de caracterizar seu campo mais próprio, resultanão-fenomenológica-istoé, resultapretensa,falsamente fenomenológica!... Não só o ser do intencional, isto é, o ser de certo ente determinado, fica sem determinar, senão que ocorrem divisões originárias no ente (consciência e realidade) sem haver-se esclarecido, ou ao menos sem haver-se questionado sobre, o sentido daquilo, precisamente o ser, com vistas ao qual se distingue. (Prolegômenos para uma história do conceito de tempo, $N \S 13-f)$.
\end{abstract} de Ser e tempo.

Restrições fomentadoras, em ampla medida, da escrita progressiva

Verifica-se assim que todas as posições e contraposições vigentes no debate Husserl/Heidegger acerca do transcendental apontam para a pergunta central sobre a possibilidade de constituição pura da realidade num âmbito irreal. Questão cujas alternativas de encaminhamento continuam vivas e abertas à investigação filosófica contemporânea, provando que, por trás das dissensões entre os dois pensadores, há a comunhão em preservar o seu vigor como questão radical, sempre reiterada. 
144

Alberto Marcos Onate

\section{REFERÊNCIAS}

COSTA, Vincenzo. La fenomenologia fra soggettività e mondo. In:

Leitmotiv, n. 3, 2003. Disponível em: <http://www.ledonline.it/leitmotiv>. Acesso em: 23 de março de 2007.

HEIDEGGER, Martin. Sein und Zeit. Tübingen: Niemeyer, 1927. Tradução brasileira: Ser e tempo. Márcia Schuback.. Petrópolis: Vozes, 1989. 2 v.

Die Grundbegriffe der Metaphysik: Welt, Endlichkeit, Einsamkeit .Prolegómenos para una historia del concepto de tiempo. Tradução de Jaime Aspiunza. Madrid: Alianza, 2006.

HUSSERL, Edmund. Husserliana - Band IX: phänomenologische psychologie. Den Haag: Martinus Nijhoff, 1962.

Husserliana - Band XXVII: Aufsätze und Vorträge(1922-1937). The Hague: Kluwer Academic Publishers, 1988.

MARION, Jean L.; PLANTY-BONJOUR, Guy (Org.). Phénoménologie et métaphysique. Paris: PUF, 1984.

\section{Bibliografia Complementar}

DUQUAIRE, Paul Victor. La naissance de l'ego husserlien et la révélation du Dasein - Etude de la phénoménalisation de l'ipséité chez Husserl et Heidegger. In: Les cahiers de l'ATP, Nice. juin/2003.

HEIDEGGER, Martin. Les problèmes fondamentaux de la phénoménologie. Traduzido do alemão por Jean-François Courtine. Paris: Gallimard, 1985.

Meine Weg in die Phänomenologie. Tübingen: Niemeyer, 1969.

Die Grundbegriffe der Metaphysik: Welt, Endlichkeit, Einsamkeit Os conceitos fundamentais da metafísica: mundo, finitude, solidão. Tradução de Marco Antonio Casanova. Rio de Janeiro: Forense, 2003.

HUSSERL, Edmund. Husserliana - Band I: cartesianische meditationen und pariser vortrage. Den. Haag: Martinus Nijhoff, 1950. 

1993.

MARION, Jean L. Réduction et donation: recherches sur Husserl, Heidegger et la phénoménologie. Paris: PUF, 1989.

Husserliana - Band VIII: erste philosophie (1923/24). Zweiter Teil Den Haag: Martinus Nijhoff, 1959.

SOUZA, R. T.; OLIVEIRA, N. F. (Org.). Fenomenologia hoje II: significado e linguagem. Porto Alegre: EDIPUCRS, 2002.

Recebido em/Received in: 08/04/2007 Aprovado em/Approved in: 17/04/2007 
